\title{
An enhanced molecular marker based genetic map of perennial ryegrass (Lolium perenne) reveals comparative relationships with other Poaceae genomes
}

\author{
Elizabeth S. J ones, Natalia L. Mahoney, Michael D. Hayward, lan P. Armstead, \\ J. Gilbert J ones, Mervyn O. Humphreys, lan P. King, Tsugutoshi Kishida, \\ Toshihiko Yamada, François Balfourier, Gilles Charmet, and J ohn W. Forster
}

\begin{abstract}
A molecular-marker linkage map has been constructed for perennial ryegrass (Lolium perenne L.) using a one-way pseudo-testcross population based on the mating of a multiple heterozygous individual with a doubled haploid genotype. RFLP, AFLP, isoenzyme, and EST data from four collaborating laboratories within the International Lolium Genome Initiative were combined to produce an integrated genetic map containing 240 loci covering $811 \mathrm{cM}$ on seven linkage groups. The map contained 124 codominant markers, of which 109 were heterologous anchor RFLP probes from wheat, barley, oat, and rice, allowing comparative relationships between perennial ryegrass and other Poaceae species to be inferred. The genetic maps of perennial ryegrass and the Triticeae cereals are highly conserved in terms of synteny and colinearity. This observation was supported by the general agreement of the syntenic relationships between perennial ryegrass, oat, and rice and those between the Triticeae and these species. A lower level of synteny and colinearity was observed between perennial ryegrass and oat compared with the Triticeae, despite the closer taxonomic affinity between these species. It is proposed that the linkage groups of perennial ryegrass be numbered in accordance with these syntenic relationships, to correspond to the homoeologous groups of the Triticeae cereals.
\end{abstract}

Key words: Lolium perenne, genetic linkage map, RFLP, AFLP, conserved synteny.

Résumé : Une carte génétique composée de marqueurs moléculaires a été produite pour l'ivraie vivace (Lolium perenne L.) à l'aide d'une population issue d'un pseudo-testcross unidirectionnel. Les parents étaient, d'une part, un individu multiple hétérozygote et, d'autre part, un génotype haploïde doublé. Des données pour des marqueurs RFLP, AFLP, isoenzymatiques ainsi que des EST ont été contribuées par quatre laboratoires faisant partie du «International Lolium Genome Initiative (ILGI) ». Ces données ont été combinées pour produire une carte génétique intégrée comprenant 240 locus, formant sept groupes de liaison et s'étendant sur $811 \mathrm{cM}$. La carte compte 124 marqueurs codominants dont 169 sont des sondes-repères RFLP hétérologues provenant du blé, de l'orge, de l'avoine ou du riz. Ces sondes permettent d'examiner les relations entre l'ivraie vivace et d'autres espèces de graminées. Les cartes génétiques de l'ivraie vivace et des céréales de la tribu des hordées sont très conservées en termes de synténie et de colinéarité. Cette conclusion s'appuie sur une concordance générale au niveau des relations de synténie entre l'ivraie vivace, l'avoine et le riz ainsi qu'entre les hordées et ces espèces. Un plus faible niveau de synténie et de colinéarité a été observé entre l'ivraie vivace et l'avoine par rapport aux hordées, malgré la proximité taxinomique entre ces espèces. Il est suggéré que les groupes de liaison chez l'ivraie vivace soient numérotés en fonction des relations de synténie de façon à correspondre aux groupes d'homéologues chez les céréales.

Received 18 April 2001. Accepted 23 October 2001. Published on the Research Press Web site 19 February 2002.

Corresponding Editor: J.P. Gustafson.

E.S. Jones, N.L. Mahoney, and J.W. Forster. ${ }^{1}$ Plant Biotechnology Centre, Agriculture Victoria, Department of Nautral Resources and Environment, La Trobe University, Bundoora, Victoria 3083, Australia; and Cooperative Research Centre for Molecular Plant Breeding, Australia.

M.D. Hayward. Rhydgoch Genetics, Rhydhir Uchaf, Comins Coch, Aberystwyth, Wales SY23 3BJ, United Kingdom.

I.P. Armstead, J.G. Jones, M.O. Humphreys, and I.P. King. Institute of Grassland and Environmental Research, Plas Gogerddan, Aberystwyth, Wales SY23 3DA, United Kingdom.

T. Kishida. Yamanashi Prefectural Dairy Experiment Station, 621 Nagasaka-Kamijo, Nagasaka, Kitakoma, Yamanashi 408, Japan.

T. Yamada. Laboratory of Grass Breeding, National Agricultural Research Centre for Hokkaido Region, National Agricultural Research Organisation, Hitsujigaoka, Sapporo 062-8555, Japan.

F. Balfourier and G. Charmet. Institut National de la Recherche Agronomique, Station d'Amelioration des Plantes, 234 avenue du Brezet, 63039 Clermont-Ferrand Cédex, France.

${ }^{1}$ Corresponding author (e-mail: john.forster@nre.vic.gov.au). 
Mots clés : Lolium perenne, carte de liaison génétique, RFLP, AFLP, conservation de la synténie.

[Traduit par la Rédaction]

\section{Introduction}

The development of molecular marker based genetic maps is an important objective for a number of forage-grass and legume crops. Although these species provide the basis for economically important grazing industries in temperate, subtropical, and tropical regions, they have been studied relatively little in terms of genome analysis, certainly when compared with other major commodities such as maize, rice, and tomato. The most important pasture-grass species for temperate zones is perennial ryegrass (Lolium perenne L.), which is cultivated for dairy, meat, and wool production and is also an important turf- and amenity-grass species (Holmes 1980). Perennial ryegrass is a member of family Poaceae and is, therefore, related to more extensively studied grass species, such as the cereals wheat, barley, maize, and rice.

Perennial ryegrass is an obligate outbreeder with a gametophytic self-incompatibility system controlled by two genetic loci designated $S$ and $Z$ (Cornish et al. 1979). To perform linkage mapping in outbreeding species, unrelated multiple heterozygous individuals can be crossed to generate $F_{1}$ progeny (a two-way pseudo-testcross; Ritter et al. 1990; Grattapaglia and Sederoff 1994) containing up to four different combinations of alleles at a single locus and up to 16 combinations at two loci. An approach that simplifies the cross structure is to mate a single heterozygous individual with a homozygous or near-homozygous tester (a one-way pseudo-testcross; Ritter et al. 1990; De Simone et al. 1997), to give a population containing a maximum of two different combinations of alleles at a single locus and four at two loci. The first genetic map for perennial ryegrass was based on such a population (p129) derived from the cross between a L. perenne $\times$ L. multiflorum interspecific hybrid and an artificial homozygote produced by anther culture (Hayward et al. 1994, 1998). The map contains 106 loci, of which, 34 are restriction fragment length polymorphisms (RFLPs) detected by Lolium cDNA and genomic DNA probes and seven are RFLPs detected with heterologous probes from oat and wheat. However, the population showed limited longevity, presumably owing to the inheritance of genes from the short-lived predominantly biennial species L. multiflorum.

Further development of the perennial ryegrass genetic map requires the use of an alternative mapping population. The $\mathrm{p} 150 / 112 \mathrm{~F}_{1}$ population was developed based on a cross between a multiple heterozygous $L$. perenne genotype of complex descent and a doubled haploid. A genetic map for this population based on dominant amplified fragment length polymorphism (AFLP) markers has already been published (Bert et al. 1999). AFLPs are suitable for mapping in oneway pseudo-testcross populations, because the two progeny classes at each locus may be distinguished, but they show reduced power in two-way pseudo-testcrosses, which are typical of trait mapping populations (Maliepaard et al. 1994), and do not usually allow genome locations to be compared across populations. For marker transfer to trait populations, codominant "framework" markers with known map locations, such as RFLPs and simple-sequence repeat polymorphisms (SSRPs), should ideally be used.

The use of heterologous RFLPs, detected by conservedsequence probes, has demonstrated that many Poaceae species (rice, maize, pearl millet, foxtail millet, maize, sorghum, sugarcane, wheat, barley, and rye; Gale and Devos 1998) have genomes that are related in terms of genetic-map segmental structure (conserved synteny) and gene order (conserved colinearity). A high level of conserved synteny and colinearity has been observed between the genetic maps of wheat, barley, and oat (Namuth et al. 1994; Van Deynze et al. 1995b,1995c; Dubcovsky et al. 1996), which all reside in the same subfamily (Pooideae) as perennial ryegrass (Soreng and Davis 1998). A high level of synteny and colinearity would, therefore, also be expected between these species and perennial ryegrass, thus permitting the crossspecies transfer of information on the genetic control of biochemical, physiological, and agronomic processes.

This paper describes the construction of an enhanced molecular-marker map for perennial ryegrass, based on the combination of marker segregation data from four laboratories within the International Lolium Genome Initiative (ILGI; Forster et al. 2001). RFLP data, obtained using heterologous probes derived from wheat, barley, oat, and rice, have been combined with AFLP data previously reported by Bert et al. (1999). Comparisons with the genetic maps of the Triticeae cereals, oat, and rice have revealed significant regions of conserved synteny and colinearity, enabling the perennial ryegrass map to be integrated with those of other Poaceae species.

\section{Materials and methods}

\section{Plant material}

The reference genetic-mapping population, p150/112, was derived from a pair cross between a multiple heterozygous L. perenne parent of complex descent (9982-1 (seed collection Romania 1980) × 3613 (early North Italian $\times$ 'Melle' or 'S23')) as pollinator and a doubled-haploid (DH290; Lolium perenne L.) as female parent. The cross was created at the Institute of Grassland and Environmental Research (IGER), Aberystwyth, U.K.; 183 progeny individuals were germinated, and clonal replicates were distributed to ILGI participant laboratories for propagation, DNA extraction, and genetic analysis. Genomic DNA was extracted by the $1 \times$ CTAB (cetyltrimethylammonium bromide) method of Fulton et al. (1995).

\section{RFLP and AFLP analysis}

PSR wheat genomic clones were provided by K. Devos and M.D. Gale of the Department of Cereals Research, John Innes Centre, Norwich, U.K (Gale et al. 1995). BCD (barley cDNA), CDO (oat cDNA), WG (wheat genomic), and RZ (rice cDNA) clones were provided by $\mathrm{S}$. McCouch of Cornell University, Ithaca, N.Y., (Van Deynze et al. 1998) and L. Larka 
of the United States Department of Agriculture. Rice C (callus) and R (root) cDNA clones were provided by the Rice Genome Research Program, Tsukuba, Japan. The ABLPG clones were derived from a $L$. perenne Pst I genomic library (Hayward et al. 1998).

Polymorphism was detected by Southern hybridization. Genomic DNA (10 $\mu \mathrm{g}$ at the Plant Biotechnology Centre, Agriculture Victoria (AV-PBC), Australia; $20 \mu \mathrm{g}$ at IGER; and $4 \mu \mathrm{g}$ at the Yamanashi Prefectural Dairy Experiment Station (YPDES), Japan) of the multiple heterozygous parent and 5-6 $F_{1}$ progeny was restricted with one or more of seven restriction enzymes (DraI, EcoRI, EcoRV, and HindIII at AV-PBC; DraI, EcoRI, EcoRV, HindIII, and BamHI at IGER; and BamHI, BglII, EcoRI, HindIII, DraI, EcoRV, and $K p n I$ at YPDES). Genomic DNA of the doubled-haploid parent was not available. Polymorphic probes were screened on a progeny set of up to 165 individuals. RFLP analysis was performed using isotopic detection, with the oligolabelling method of Feinberg and Vogelstein (1984) and the hybridization conditions of Sharp et al. (1988) (AV-PBC) or using the ECL (enhanced chemiluminesence) direct nucleic acid labelling and detection kit (Amersham) (IGER and YPDES).

AFLP analysis was performed as described by Bert et al. (1999). The isoenzyme-marker loci PGM, GOT/3, and ACP/2 were analysed according to Hayward et al. (1995) and the expressed sequence tag (EST) markers OSE, OSRB, OSW, LP1, and MZE were previously described by Lallemand et al. (1998) and Bert et al. (1999).

\section{Genetic-map construction}

The markers, which had unknown phase, were grouped using JOINMAP 2.0 ${ }^{\mathrm{TM}}$ (Stam and van Ooijen 1995) with an LOD threshold of 6.0 to give six linkage groups (LG1LG6). The phase of markers within each group was again determined using MAPMAKER 3.0 (Lander et al. 1987), and one linkage group was split in two at LOD 8.0. Markers were ordered in MAPMAKER at LOD >2.0, and the orders tested using the ripple command. Map distances were calculated using the Kosambi mapping function (Kosambi 1944).

Comparative genetic map analysis with the Triticeae was performed using data derived from GrainGenes (http:// genome. cornell.edu/cgi-bin/WebAce/webace $? \mathrm{db}=$ graingenes), with special reference to the consensus maps of Triticeae groups 1-3 and six chromosomes (Nelson et al. 1995a, 1995b; Van Deynze et al. 1995a; Marino et al. 1996; http://ars-genome.cornell.edu/cgi-bin/WebAce/webace?db= graingenes\&class $=$ Map_Date\&object $=$ Triticeae $\% 20$ consensus \&display=text); the consensus map of hexaploid wheat (Gale et al. 1995; "Gale Multi-Map" at http://genome.cornell. edu/cgi-in/WebAce/webace?db=graingenes\&class=MultiMap); the probe repository chromosome allocations (http:// wheat.pw.usda.gov/ggpages/probes); and the chromosomearm maps for wheat (Anderson et al. 1992). Linkage groups were assigned and numbered in accordance with observed conserved synteny with the genetic maps of the Triticeae cereal species.

Comparative genetic analysis with oat was performed by comparison with the oat map of Van Deynze et al. (1995b) and through data derived from GrainGenes. Comparative ge-
Table 1. RFLP detection in the p150/112 family by heterologous anchor probes from other Poaceae species.

\begin{tabular}{lcc}
\hline $\begin{array}{l}\text { Anchor probe } \\
\text { class }^{a}\end{array}$ & $\begin{array}{l}\text { No. of } \\
\text { probes }\end{array}$ & $\begin{array}{l}\text { Polymorphism } \\
(\%)^{b}\end{array}$ \\
\hline PSR & 97 & 42 \\
WG & 2 & 100 \\
BCD & 24 & 58 \\
CDO & 74 & 67 \\
RZ & 6 & 83 \\
C and R & 89 & 36 \\
All & 292 & 48 \\
\hline \multicolumn{2}{c}{${ }^{a}$ PSR, wheat genomic DNA and cDNA; WG, } \\
wheat genomic DNA; BCD, barley cDNA; CDO, oat \\
cDNA; RZ, C, and R, rice cDNA. \\
${ }^{b}$ Percentage of probes screened.
\end{tabular}

netic map analysis with rice was performed using data derived from the Integrated Rice Genome Explorer database (http://rgp.dna.affrc.go.jp/giot/INE.html) and RiceGenes (Causse et al. 1994; Kurata et al. 1994; Harushima et al. 1998; Shen et al. 1998; http://ars-genome.cornell.edu/cgi-bin/ WebAce/webace?db=ricegenes).

\section{Results}

\section{RFLP detection in the p150/112 family}

Two hundred and ninety-two heterologous probes were screened (97 PSR, $24 \mathrm{BCD}, 74 \mathrm{CDO}, 2 \mathrm{WG}, 6 \mathrm{RZ}$, and 89 rice $\mathrm{C}$ and $\mathrm{R}$ cDNA clones). The intensity and clarity of the hybridization signals showed considerable variation. In the case of the rice $\mathrm{C}$ and $\mathrm{R}$ cDNA probes, $13 \%$ of the hybridized probes detected no bands (data not shown). Only $17 \%$ detected clear bands, with the remaining $70 \%$ detecting faint or smeared bands that were more difficult to interpret. In contrast, all the wheat, barley, and oat probes detected a visible signal. Wheat and oat probes detected similar numbers of clear bands ( 52 and $43 \%$, respectively); both detected larger numbers of clear bands than barley probes $(27 \%)$.

Polymorphism was detected by $48 \%$ (140) of the heterologous probes that were screened, with different probe classes detecting different levels of polymorphism (Table 1). The restriction enzyme DraI detected the highest levels of polymorphism (25\%), with lower levels being detected by other enzymes (data not shown). In addition, a small number of polymorphic markers (five) were identified by homologous probes derived from the ABLPG probe set (Hayward et al. 1998).

Multiple loci were detected by 16 probes and were independently scored.

\section{Mapping data}

RFLP and AFLP data were obtained for an average of 96 $\mathrm{F}_{1}$ genotypes (with a range from 30 to 145). The 175 AFLP markers selected by Charmet et al. (2000) for their ability to provide good genome coverage with a minimal number of primers were included in this study. An additional 17 AFLP markers were selected from the original map of Bert et al. (1999), to include loci at the ends of linkage groups that 
Table 2. Composition of the consolidated International Lolium Genome Initiative marker data set.

\begin{tabular}{llcllr}
\hline Molecular marker locus class & AV-PBC & IGER & NARCH & INRA & Total \\
\hline PSR-detected RFLP & 31 & - & - & - & 31 \\
BCD-detected RFLP & 11 & 4 & - & - & 15 \\
CDO-detected RFLP & 25 & 21 & - & - & 46 \\
WG-detected RFLP & 1 & 1 & - & - & 2 \\
RZ-detected RFLP & - & 3 & - & - & 3 \\
C- and R-detected RFLP & - & - & 40 & - & 40 \\
ABLPG-detected RFLP & - & 6 & - & - & 6 \\
EcoRI/MseI AFLP & - & - & - & 2 & 192 \\
Isoenzyme & - & 1 & - & 5 & 3 \\
ESTs & - & - & - & 199 & 343 \\
Total & 68 & 36 & 40 & - \\
\hline
\end{tabular}

Note: AV-PBC, Plant Biotechnology Centre at Agriculture Victoria (Australia); IGER, Institute of Grassland and Environmental Research (United Kingdom); YPDES/NARCH, Yamanashi Prefectural Dairy Experiment Station/National Agricultural Research Centre for Hokkaido Region (Japan); INRA, L'Institut National de la Recherche Agronomique (France).

were not selected by Charmet et al. (2000). Table 2 shows the composition of the consolidated data set.

\section{Genetic-map construction}

Of the 342 loci (including duplicated loci detected by a single RFLP probe), JOINMAP $2.0^{\mathrm{TM}}$ excluded 20 RFLP loci from grouping based on modified LOD scores of pairs of markers, which tends to avoid spurious linkage of markers showing distorted segregations. The remaining 322 markers were grouped into six linkage groups at LOD 6.0, one less than the karyotypic number for perennial ryegrass $(x=7)$. Several considerations suggested that one of the linkage groups should be split into two. First, a high proportion of the markers on the linkage group in question showed distorted segregations, with $54 \%$ being skewed at $P<0.05$. Such deviations from Mendelian expectation may result in spurious linkages. Second, following three-point analysis, MAPMAKER 3.0 experienced considerable difficulty in ordering the markers within the linkage group. Third, the AFLP loci in this linkage group had originally been mapped to two linkage groups (Bert et al. 1999), and two RFLP loci (R1613 and CDO580) had been mapped to separate linkage groups in a different L. perenne mapping population (I.P. Armstead, unpublished data). In an attempt to break this linkage group, markers that skewed at $P<0.05$ were removed from the data set, but the same linkage groups were formed at LOD 5.0. However, a split into two groups in the expected place was achieved by increasing the threshold for grouping to LOD 8.0 (in MAPMAKER 3.0), to generate LG1 and LG3.

Markers within linkage groups were ordered using MAPMAKER 3.0. Seven RFLP loci were not included, as their map locations were either more than $40 \mathrm{cM}$ beyond the ends of the relevant linkage groups or more than $30 \mathrm{cM}$ and mapped using fewer than 80 progeny individuals. When AFLP loci were co-located, only one of the markers was included in the final map. The final linkage map contained 240 markers, with between 25 and 49 markers per linkage group (Fig. 1). Of the total number of markers, 124 were codominant, of which 109 were heterologous RFLPs. There were several markers on each linkage group that could not be ordered at LOD >2.0, but these tended to occur within small map distances (Fig. 1, bracketed markers). The smallest and largest unordered regions were 0.7 and $18 \mathrm{cM}$ (average of $4.5 \mathrm{cM}$ ) in length, respectively. Individual linkage groups were between 90 and $136 \mathrm{cM}$ in length and covered a total map distance of $811 \mathrm{cM}$. The maximum distance between markers was $25 \mathrm{cM}$ and the average distance was $3 \mathrm{cM}$.

Twenty-two percent of all mapped markers (52/241) showed distorted segregation at $P<0.05$ and $8 \%(20 / 241)$ showed distorted segregation at $P<0.01$. As the AFLP markers had previously been selected for their low levels of distortion (Bert et al. 1999), codominant markers were considered alone and were found to show $32 \%$ distorted segregation at $P<0.05$ and $15 \%$ distorted segregation at $P<$ 0.01 . The highest concentration of skewed markers occurred on LG3, with smaller numbers clustering on LG4 and LG5 (Fig. 1). Selection consistently occurred against alleles of the same phase for skewed markers within the same linkage group.

\section{Comparison with previous perennial ryegrass genetic maps}

The perennial ryegrass linkage groups in this study were numbered in accordance with the corresponding linkage groups of the Triticeae cereals on the basis of conserved synteny (see below). Consequently, the numerical order is not in agreement with the alphabetical order used for the previously published AFLP map derived from this cross (Bert et al. 1999; Charmet et al. 2000). LG1 here corresponds to AFLP group G, LG2 to group B, LG3 to group E, LG4 to group C, LG5 to group D, LG6 to group F, and LG7 to group A. For three of the seven linkage groups, AFLP markers were colinear with those published by Charmet et al. (2000). For the remaining linkage groups, the addition of the codominant marker data caused order changes within four regions, but these all occurred within distances of less than $4 \mathrm{cM}$. 


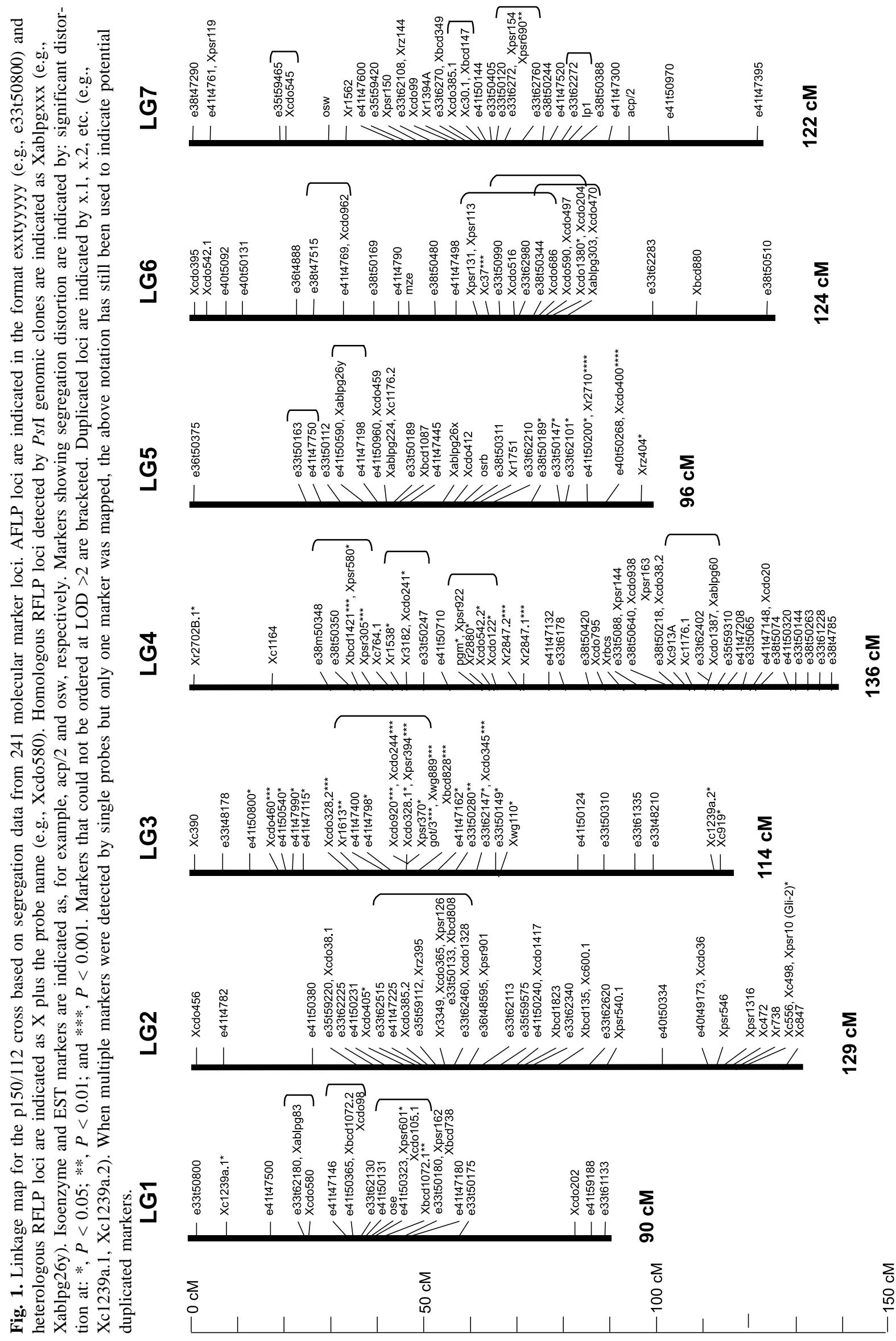


Alignment of the present genetic map with the first molecular marker based map of perennial ryegrass (Hayward et al. 1998) was problematic, owing to the limited number of common markers detecting a single locus. The isozyme locus got/3 mapped to LG3 in this study and to LG2 in the map of Hayward et al. (1998). The isozyme locus pgm mapped to LG4 in this study and LG5 in the map of Hayward et al. (1998).

\section{Comparative map relationships}

Conserved syntenic relationships between perennial ryegrass linkage groups and the maps of the Triticeae, rice, and oat are shown in Fig. 2. Here we have defined a syntenic chromosomal segment as one containing a group of syntenic markers that is interrupted by no more than one nonsyntenic locus. Not all the heterologous probes that were mapped in perennial ryegrass could be assigned to corresponding positions in each of the Triticeae, rice, and oat maps. Seventy-six markers could be assigned to chromosomal locations on the Triticeae consensus map, which covered $70 \%$ of the perennial ryegrass map (Table 3). Within these regions, LG1, LG3, and LG5 showed complete synteny with the corresponding chromosomes of the Triticeae. LG2, LG4, and LG7 each contained small nonsyntenic regions, and LG6 contained a larger nonsyntenic region. Overall, $80 \%$ of markers common to the perennial ryegrass and Triticeae maps were syntenic (Table 3). An accurate assessment of colinearity was difficult, owing to the necessity for comparison with several different Triticeae genetic maps. However, if the bracketed markers (those that could not be ordered at LOD >2.0) on the map shown in Fig. 2 are considered to have a flexible order, colinearity within syntenic regions appeared to be completely conserved.

A smaller number of markers were located on the oat map (45) and these covered $50 \%$ of the perennial ryegrass map (Table 3). Perennial ryegrass linkage groups LG1-LG6 contained large regions that were syntenic with parts of oat chromosomes A-G (not in the same order), with three linkage groups showing syntenic relationships with more than one oat chromosome: LG3 with oat chromosomes $\mathrm{C}$ and $\mathrm{G}$, LG4 with oat chromosomes F and E, and LG6 with oat chromosomes D and G. No syntenic relationship between perennial ryegrass LG7 and any oat chromosome could be found. Overall, 66\% of markers common to the perennial ryegrass and oat maps were syntenic (Table 3). Within syntenic regions, colinearity was conserved within LG1, LG3, and LG4, but not within LG2 and LG5. LG6 contained only two markers that were syntenic in each of the two oat segments, so colinearity could not be assessed.

Sixty-six percent of the perennial ryegrass map was covered by 93 markers with known map locations in rice (Table 3). Within these regions, LG1 and LG7 were the only linkage groups that showed complete synteny with rice chromosomes. Four perennial ryegrass linkage groups showed syntenic relationships with two or more rice chromosomes: LG2 with rice chromosomes 7, 4, and 6; LG3 with rice chromosomes 1 and 5; LG5 with rice chromosomes 9 and 2; and LG7 with rice chromosomes 6 and 8. Overall, 63\% of the markers common to the perennial ryegrass and rice maps were syntenic (Table 3). An accurate assessment of colinearity was difficult, owing to comparisons between several different rice genetic maps. However, it appeared that, within the syntenic regions, colinearity was conserved for all linkage groups, except within a small region on LG5.

\section{Discussion}

We have constructed a linkage map for perennial ryegrass containing substantial numbers of regularly spaced codominant markers that may be used to anchor linkage groups in subsequent genetic-mapping crosses. The use of heterologous probes has facilitated the integration of the perennial ryegrass genetic map with those of the Triticeae cereals. A high level of conserved synteny between perennial ryegrass and the Triticeae species, as well as the presence of a common fundamental chromosome number $(x=7)$, has allowed the numerical assignment of perennial ryegrass linkage groups to coincide with those of the Triticeae. This novel approach to assigning linkage groups will simplify comparative genetics and genomics and facilitate the transfer of biochemical, genetical, and physiological information from well-studied cereal species to perennial ryegrass.

The use of heterologous anchor probes to detect RFLP is constrained by two factors: the ability to efficiently detect conserved sequences (putative ortholoci) by hybridisation and the level of genetic polymorphism detected using a selected set of restriction endonucleases. In this study, comparisons between probe types was particularly difficult, owing to variations in specific laboratory protocols. In general terms, wheat, oat, and barley probes gave higher levels of clear hybridisations than rice probes. This trend follows current taxonomic knowledge of the Poaceae, as wheat, oat, barley, and perennial ryegrass reside in a different subfamily than rice (Soreng and Davis 1998). The differences in effective polymorphism detected by different probe classes largely reflect this variation in ortholocus detection, with deviations being attributable to small sample sizes. As has been observed in previous studies (e.g., Wang and Tanksley 1989; Miller and Tanskley 1990), variation due to the choice of restriction endonuclease was found. The enzyme DraI revealed the highest level of polymorphism, possibly because DraI recognition sites (5'-TTTAAA-3') may tend to cluster in AT-rich and variable intergenic DNA sequences.

The present genetic map builds on the work of Bert et al. (1999), in which 17 primer combinations were used to generate 463 mapped AFLP loci. AFLP markers have several disadvantages: they show reduced power in genetic mapping and quantitative trait locus (QTL) location compared with codominant markers, they are not readily used in framework mapping, and they cannot be used in comparative mapping. However, a large number of markers can be readily generated to give substantial genome coverage, therefore facilitating linkage between framework codominant markers. For this reason, the AFLP markers that were mapped in this cross significantly assisted in the construction of the present map.

The AFLP data of Bert et al. (1999) were subsequently reduced through the use of a computerised algorithm that was developed to select evenly spaced markers using a minimal number of selective primer combinations (Charmet et al. 2000). The algorithm selected 175 markers amplified by six primer pairs, but suffered the disadvantage that some AFLP 


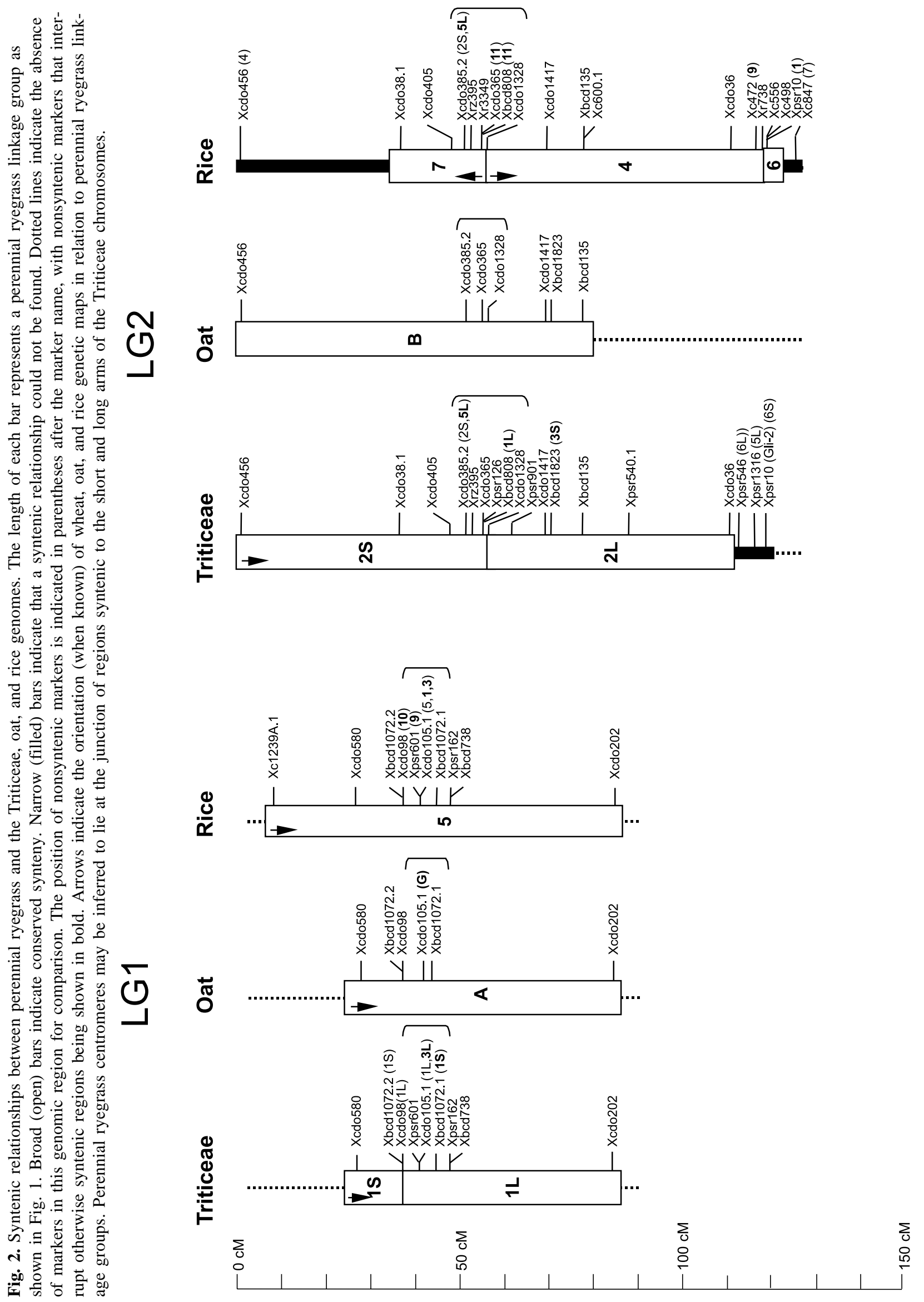



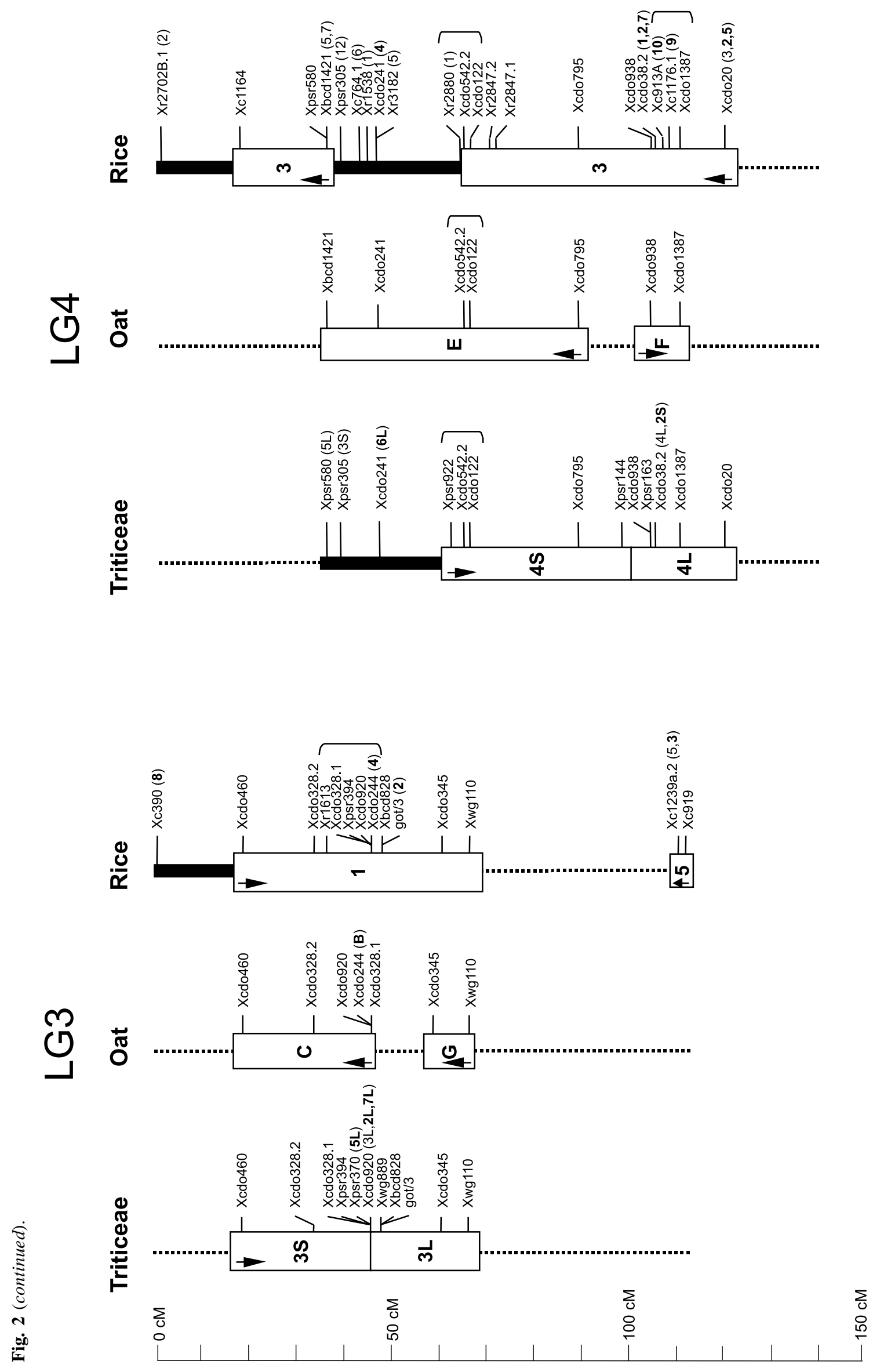

(C) 2002 NRC Canada 

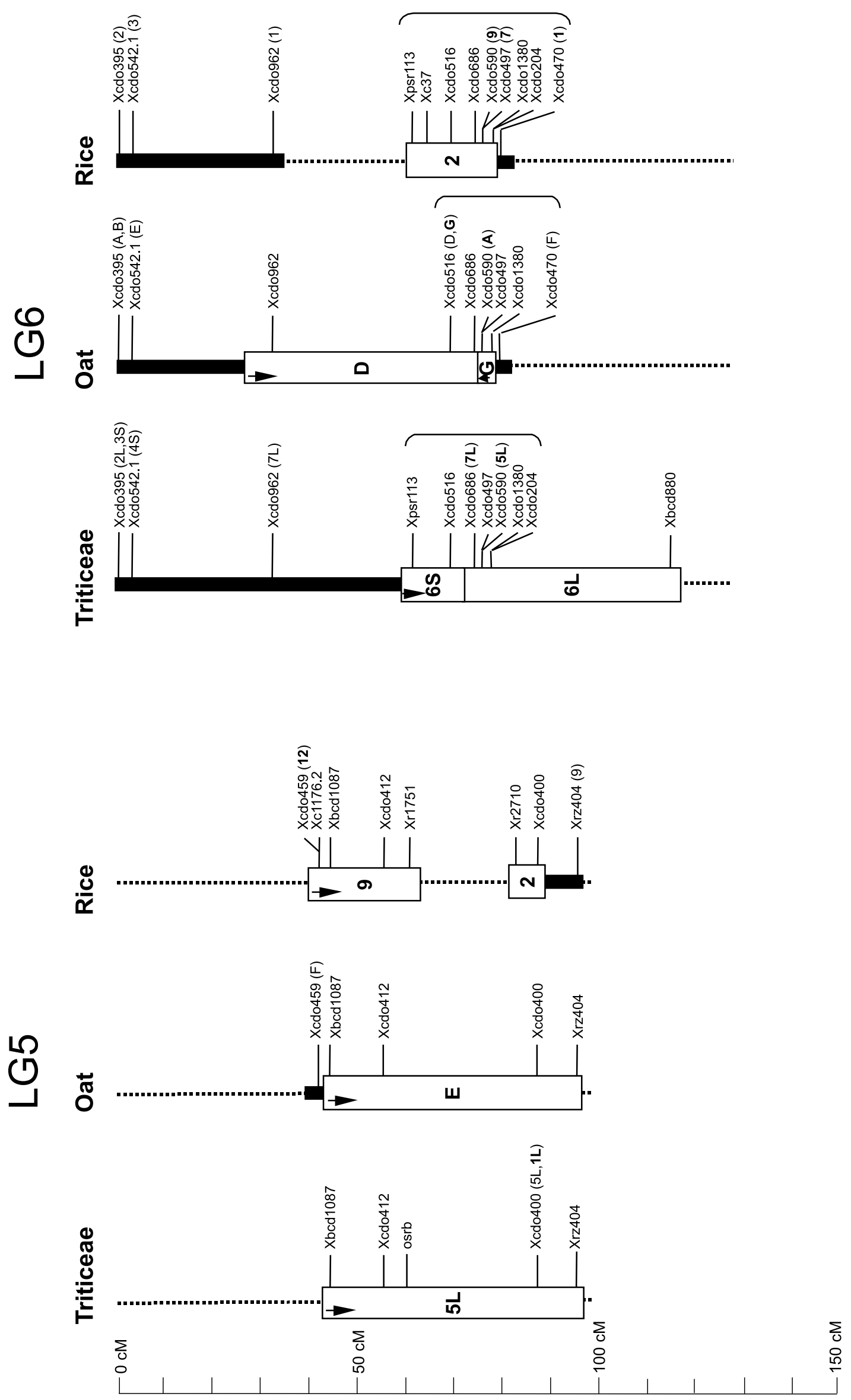

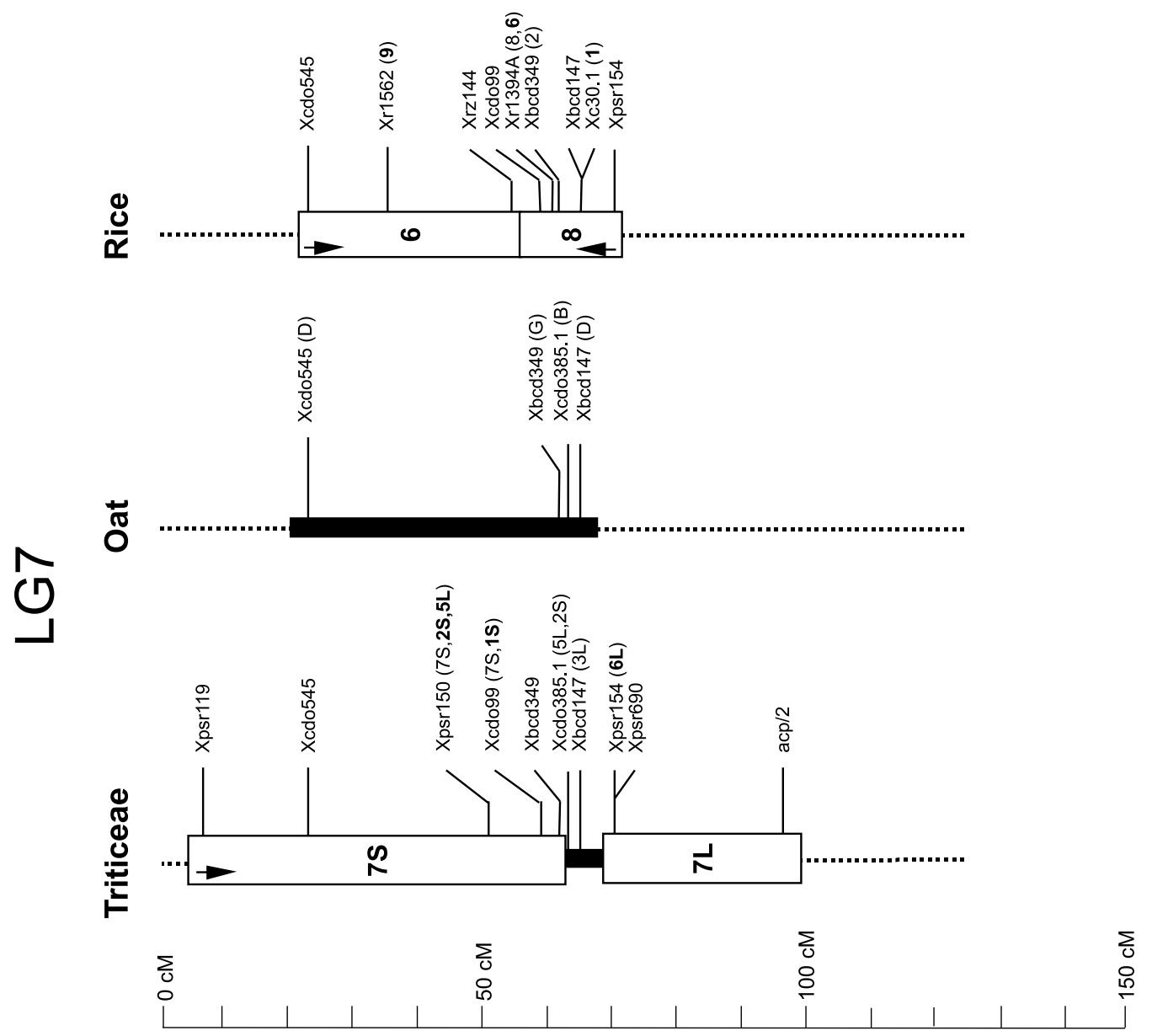

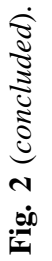


Table 3. Genome comparisons between perennial ryegrass and the Triticeae cereals, oat, and rice.

\begin{tabular}{llll}
\hline & \multicolumn{3}{l}{$\begin{array}{l}\text { Markers with known map } \\
\text { locations in: }\end{array}$} \\
\cline { 2 - 4 } & Triticeae & oat & rice \\
\hline $\begin{array}{c}\text { No. of markers mapped in } \\
\text { perennial ryegrass }\end{array}$ & 76 & 45 & 93 \\
$\begin{array}{c}\text { Genome coverage in perennial } \\
\text { ryegrass }(\%)\end{array}$ & 70 & 50 & 66 \\
\begin{tabular}{c} 
Conserved synteny $(\%)$ \\
\hline
\end{tabular} & 80 & 66 & 63 \\
\hline
\end{tabular}

loci mapping to the ends of each linkage group were not selected. Here we reselected an additional 17 distal AFLP markers, and these markers greatly aided in locating to the ends of linkage groups some of the RFLPs that would otherwise have remained unlinked. The largest loss of genome coverage was for the ends of LG1, LG2, and LG6. We recommend that an additional two primer combinations $(\mathrm{e} 40 \mathrm{t} 50=E c o \mathrm{RI}+\mathrm{AGC} / \mathrm{Tr}$ $91+\mathrm{CAT}$ and $\mathrm{e} 41 \mathrm{t} 59=$ $E c o$ RI + AGG/Tru91 + CTA) be used to cover these linkage group ends, or else that the statistical threshold for selection of primer pairs within the developed algorithm be relaxed for more complete genome coverage.

The total map distance covered here was $811 \mathrm{cM}$. This is similar to the value of $793 \mathrm{cM}$ derived by Bert et al. (1999) and, given the greater number of markers mapped here, is not inconsistent with the $692 \mathrm{cM}$ covered in the map of Hayward et al. (1998). The haploid genome size of perennial ryegrass has been estimated at ca. $1.6 \times 10^{9} \mathrm{bp}$, based on a 2C nuclear DNA content of 4.16 pg (Hutchinson et al. 1979). These values suggest an average value of $1.85 \times 10^{6}$ $\mathrm{bp} / \mathrm{cM}$ for perennial ryegrass. This is larger than the value of $1.91 \times 10^{5} \mathrm{bp} / \mathrm{cM}$ for the much smaller rice genome, comparable to the value of $1.1 \times 10^{6} \mathrm{bp} / \mathrm{cM}$ for the similarly sized maize genome, and smaller than the value of $3.4 \times 10^{6}$ $\mathrm{bp} / \mathrm{cM}$ for the larger barley genome (Shields 1993).

A large number of markers showing segregation distortion were observed in this cross, with the largest cluster occurring on LG3. At $P<0.01$, segregation distortion was observed in $8 \%$ of the total number of markers mapped and $15 \%$ of the codominant markers. As would be expected, these figures are lower than the level of distortion of $20 \%$ at $P<0.01$ observed in the interspecific L. perenne $\times$ L. multiflorum cross used for mapping by Hayward et al. (1998). In both these studies, however, skewed markers tended to cluster, with two regions of skewed markers being observed by Hayward et al. (1998) and three regions being observed here. It is possible that regions of the genome with significant segregation distortion are associated with self-incompatibility genes, as a result of partial identity between the genotypes of the male and female parents at the $S$ and $Z$ loci. For this particular cross structure, linked marker alleles would show a 2:1 inheritance ratio compared with the $1: 1$ ratio expected for loci elsewhere in the genome. This level of distortion was met by several of the mapped markers. However, given the high frequency of self-incompatibility alleles found in single populations (Devey et al. 1994; Fearon et al. 1994) and the diverse origin of the parents used in this cross, it seems un- likely that the parents would share common alleles. In addition, the limited level of map alignment afforded by markers common to this linkage map and that of Hayward et al. (1998) suggests that the regions of distorted segregation are not the same. The observed skewed regions are more likely to be associated with loci affecting gametophytic or sporophytic viability, which have been found in previous studies (e.g., Guo et al. 1991).

A small number (seven) of mapped RFLP probes detected duplicated loci in the current map, both within and between linkage groups. However, large regions of duplication could not be detected. Most flowering plant genomes are thought to have gone through one or more cycles of polyploid formation and duplication (Stebbins 1966; Helentjaris et al. 1988; Masterson 1994), with even the streamlined genome of Arabidopsis thaliana containing ancient chromosomal duplication (Blanc et al. 2000; Ku et al. 2000). Although a low level of duplication was apparent in this map and also in that of Hayward et al. (1988), intragenomic segmental duplication does not seem to have been a major factor in the recent evolution of perennial ryegrass.

Comparative map analysis with other members of the Poaceae demonstrated significant conserved synteny, particularly with the Triticeae cereal species. Each linkage group contained segments that were syntenic and colinear with the corresponding homoeologous groups of the Triticeae species. Syntenic segments covered a large proportion of each perennial ryegrass linkage group and enabled centromeric positions to be inferred in perennial ryegrass. Single markers that did not correspond to the expected linkage group were observed, interrupting otherwise syntenic linkage blocks. This effect could be the result of gene loss or divergence after duplication, which can contribute to deviations from synteny ( $\mathrm{Ku}$ et al. 2000; Paterson et al. 2000). In this context, it is interesting to note that the estimated sequence copy numbers were higher for a small number of selected probes detecting nonsyntenic marker loci than for an equivalent number of randomly selected probes detecting syntenic marker loci (data not shown).

Within the current scheme of relationships, no observable large-scale chromosomal rearrangements could be identified to differentiate the genomes of the Triticeae cereals from perennial ryegrass. This conclusion must, however, be treated with caution, as the density of the current map is insufficient to observe small-scale duplications and rearrangements (Paterson et al. 2000). In addition, information is not available from the large terminal segments mapped here that contain a preponderance of AFLP markers. For comparisons between maize and sorghum, increasing marker density and genome coverage revealed new rearrangements that had not originally been found (Pereira et al. 1994). Likewise, assessments of colinearity should also be treated with caution, particularly as the size of the population used to construct this map was small, which can result in ambiguous gene ordering (Paterson et al. 2000). From a different perspective, the observed high level of colinearity found between perennial ryegrass and the Triticeae cereal species supports the marker orders found in this map. The comparative relationships may even be tentatively used to assign putative orders to markers that could not be ordered at LOD $>2.0$. 
The alignment of the ryegrass map with those of the Triticeae cereals confirms the relatively close taxonomic relationship of genus Lolium to the Triticeae genera Triticum, Hordeum, and Secale, which all reside within subfamily Pooideae. This relationship is further confirmed through examination of the relationships of perennial ryegrass with oat and rice, which closely follow the relationships that have previously been found between the Triticeae and these species (Van Deynze et al. 1995b, 1995c). Van Deynze et al. $(1995 c)$ found 16 regions that were conserved between the Triticeae and oat. If we consider perennial ryegrass linkage groups to be closely aligned with the Triticeae, we would expect the same 16 regions to be conserved between perennial ryegrass and oat. In fact, 10 of the same segments were conserved and four were not detected, owing to a lack of common markers in the relevant regions. The only major discrepancy was for LG6, which was expected to show synteny with oat chromosomes A, B, and G but, instead, was syntenic with chromosomes D and G. Similarly, of the 16 segments conserved between the Triticeae and rice (Van Deynze et al. 1995c), most were also conserved between perennial ryegrass and rice. There are three basic rearrangements that define the relationship between the Triticeae and rice genomes: R8 inserted into R6 to form Triticeae group 7, R7 inserted into R4 to form Triticeae group 2, and R10 inserted into R5 to form Triticeae group 1 (Devos and Gale 1997). Of these, we have good evidence that perennial ryegrass has the former two rearrangements, with the latter being suggested through the presence of a single R10 marker within R5.

Perennial ryegrass appears to be more closely related to the Triticeae than to oat in terms of genome structure, despite the closer taxonomic affinity that exists between perennial ryegrass and oat. Perennial ryegrass and oat belong to the same supertribe, Poodae, while the Triticeae belong to a different supertribe, Triticodae, within the same subfamily, Pooideae (Soreng and Davis 1998). The genomic rearrangements in oat that separate it from the Triticeae and perennial ryegrass must have occurred after the divergence of the Poodae. Similarly, rye and Aegilops umbellulata, which are closely related to wheat in terms of taxonomy, have quite divergent genome structures (Rognli et al. 1992; Devos et al. 1993; Zhang et al. 1998). Clearly, the number of evolutionary rearrangements distinguishing taxa does not provide a good measure of evolutionary distance, and there is currently no clear explanation for why certain species accumulate and fix rearrangements more readily than others (Devos and Gale 1997).

Our ultimate goal is to use this comparative information to locate genes of common function across species. The ortholoci in perennial ryegrass of the well-characterised and conserved vernalisation ( $V r n l)$ loci on the homoeologous group 5 chromosomes of wheat (Halloran 1976; Sarma et al. 2000) and the photoperiod response (Ppdl) loci on the homoeologous group 2 chromosomes of wheat (Law et al. 1978) are of special interest. Relatively understudied species such as perennial ryegrass may gain the most from comparative genetics, although specific loci in $L$. perenne for which there are no known orthologues in the cereals, such as those controlling perenniality, will be of considerable interest to cereal breeders. This genetic map succeeds in aligning the perennial ryegrass genome with those of well-studied Poaceae species, thus laying the foundation for these goals to be achieved.

\section{Acknowledgements}

At AV-PBC, this research was supported by the Cooperative Research Centre (CRC) for Molecular Plant Breeding (MPB) and the Victorian Department of Natural Resources and Environment. Natalia Mahoney was the recipient of a CRC MPB postgraduate studentship. L'Institut National de la Recherche Agronomique would like to thank P.F. Bert for his contribution towards the generation of the AFLP data and J. Lallemand for providing ESTs. At YPDES, this research was funded by the Ministry of Agriculture, Forestry and Fisheries, with the cooperation of the Rice Genome Research Program. At IGER, this research was supported by the Biotechnology and Biological Sciences Research Council (BBSRC).

\section{References}

Anderson, J.A., Ogihara, Y., Sorrells, M.E., and Tanksley, S.D. 1992. Development of a chromosome arm map for wheat based on RFLP markers. Theor. Appl. Genet. 83: 1035-1043.

Bert, P.F., Charmet, G., Sourdille, P., Hayward, M.D., and Balfourier, F. 1999. A high-density molecular map for ryegrass (Lolium perenne L.) using AFLP markers. Theor. Appl. Genet. 99: 445-452.

Blanc, G., Barakat, A., Guyot, R., Cooke, R., and Delseny, M. 2000. Extensive duplication and reshuffling in the Arabidopsis genome. Plant Cell, 12: 1093-1101.

Causse, M.A., Fulton, T.M., Cho, Y.G., Ahn, S.N., Chunwongse, J., Wu, K., Xiao, J., Yu, Z., Ronald, P.C., Harrington, S.E., Second, G., McCouch, S.R., and Tanksley, S.D. 1994. Saturated molecular map of the rice genome based on an interspecific backcross population. Genetics, 138: 1251-1274.

Charmet, G., Bert, P.F., and Balfourier, F. 2000. A computerised algorithm for selecting a subset of multiplex molecular markers and optimising linkage map construction. Theor. Appl. Genet. 101: 90-94.

Cornish, M.A., Hayward, M.D., and Lawrence, M.J. 1979. Selfincompatibility in ryegrass. I. Genetic control in diploid Lolium perenne L. Heredity, 43: 95-106.

De Simone, M., Morgante, M., Lucchin, M., Parrini, P., and Marocco, A. 1997. A first linkage map of Cichorium intybus L. using a one-way pseudo-testcross and PCR-derived markers. Mol. Breed. 3: 415-425.

Devey, F., Fearon, C.H., Hayward, M.D., and Lawrence, M.J. 1994. Self-incompatibility in ryegrass. XI. Number and frequency of alleles in a cultivar of Lolium perenne L. Heredity, 73: $262-264$.

Devos, K.M., and Gale, M.D. 1997. Comparative genetics in the grasses. Plant Mol. Biol. 35: 3-15.

Devos, K.M., Milan, T., and Gale, M.D. 1993. Comparative RFLP maps of the homoeologous group-2 chromosomes of wheat, rye and barley. Theor. Appl. Genet. 85: 784-792.

Dubcovsky, J., Luo, M.-C., Zhong, G.-Y., Bransteitter, R., Desai, A., Kilian, A., Kleinhofs, A., and Dvořák, J. 1996. Genetic map of diploid wheat (Triticum monococcum L.) and its comparison with maps of Hordeum vulgare L. Genetics, 143: 983-999. 
Fearon, C.H., Cornish, M.A., Hayward, M.D., and Lawrence, M.J. 1994. Self-incompatibility in ryegrass. X. Number and frequency of alleles in a natural population of Lolium perenne $\mathrm{L}$. Heredity, 73: 254-261.

Feinberg, A.P., and Vogelstein, B. 1984. A technique for radiolabelling DNA restriction endonuclease fragments to high specific activity. Anal. Biochem. 132: 6-13.

Forster, J.W., Jones, E.S., Kölliker, R., Drayton, M.C., Dumsday, J., Dupal, M.P., Guthridge, K.M., Mahoney, N.L., van Zijll de Jong, E., and Smith, K.F. 2001. Development and implementation of molecular markers for forage crop improvement. In Proceedings of the 2nd International Symposium on Molecular Breeding of Forage Crops, held Lorne and Hamilton, Victoria, Australia, 19-24 November 2000. Edited by G. Spangenberg. Kluwer Academic Publishers, Dordrecht, The Netherlands. pp. 101-133.

Fulton, T.M. Chunwongse, J., and Tanksley, S.D. 1995. Microprep protocol for extraction of DNA from tomato and other herbaceous plants. Plant Mol. Biol. Rep. 13: 207-209.

Gale, M.D., and Devos, K.M. 1998. Plant comparative genetics after 10 years. Science (Washington, D.C.), 282: 656-659.

Gale, M.D., Atkinson, M.D., Chinoy, C.N., Harcourt, R.L., Jia, J., Li, Q.Y., and Devos, K.M. 1995. Genetic maps of hexaploid wheat. In Proceedings of the 8th International Wheat Genetics Symposium, held Beijing, China, 20-25 July 1993. Edited by Z.S. Li and Z.Y. Xin. China Agricultural Scientech Press, Beijing. pp. 29-40.

Grattapaglia, D., and Sederoff, R. 1994. Genetic linkage maps of Eucalyptus grandis and Eucalyptus urophylla using a pseudotestcross: mapping strategy and RAPD markers. Genetics, 137: 1121-1137.

Guo, M., Lightfoot, D.A., Mok, M.C., and Mok, D.W.S. 1991. Analysis of Phaseolus vulgaris L., and P. coccineu Lam. Hybrids by RFLP: preferential transmission of $P$. vulgaris alleles. Theor. Appl. Genet. 81: 703-709.

Halloran, G.M. 1976. Genes for vernalisation response in homoeologous group 5 of Triticum aestivum. Can. J. Genet. Cytol. 18: 211-216.

Harushima, Y., Yano, M., Shomura, A., Sato, M., Shimano, T., Kuboki, Y., Yamamoto, T., Lin, S.Y., Antonio, B.A., Parco, A., Kajiya, H., Huang, N., Yamamoto, K., Nagamura, Y., Kurata, N., Khush, G.S., and Sasaki, T. 1998. A high density rice genetic linkage map with 2275 markers using a single $F_{2}$ population. Genetics, 148: 479-494.

Hayward, M.D., McAdam, N.J., Jones, J.G., Evans, C., Evans, G.M., Forster, J.W., Ustin, A., Hussain, K.G., Quader, B., Stammers, M., and Will, J.A.K. 1994. Genetic markers and the selection of quantitative traits in forage grasses. Euphytica, 77: 269275.

Hayward, M.D., Degenaars, G.H., Balfourier, F., and Eickmeyer, F. 1995. Isozyme procedures for the characterisation of germplasm, exemplified by the collection of Lolium perenne $\mathrm{L}$. Genet. Resour. Crop. Evol. 42: 327-337.

Hayward, M.D., Forster, J.W., Jones, J.G., Dolstra, O., Evans, C., McAdam, N.J., Hossain, K.G., Stammers, M., Will, J.A.K., Humphreys, M.O., and Evans, G.M. 1998. Genetic analysis of Lolium. I. Identification of linkage groups and the establishment of a genetic map. Plant Breed. 117: 451-455.

Helentjaris, T., Weber, D., and Wright, S. 1988. Identification of the genomic locations of duplicate nucleotide sequences in maize by analysis of restriction fragment length polymorphisms. Genetics, 118: 353-363.

Holmes, W. 1980. Grass: its production and utilisation. Blackwell Scientific Publications, Oxford.
Hutchinson, J., Rees, H., and Seal, A.G. 1979. An assay of the activity of supplementary DNA in Lolium. Heredity, 43: 411-421.

Kosambi, D.D. 1944. The estimation of map distances from recombination values. Ann. Eugen. 12: 172-175.

Ku, H.M., Vision, T., Liu, J., and Tanksley, S.D. 2000. Comparing sequenced segments of the tomato and Arabidopsis genomes: large-scale duplication followed by selective gene loss creates a network of synteny. Proc. Natl. Acad. Sci. U.S.A. 97: 91219126.

Kurata, N., Nagamura, Y., Yamamoto, K., Sue, N., Wu, J., Antonio, B.A., Shomura, A., Shimizu, T., Lin, S.Y., Inoue, T., Fukuda, A., Shimano, T., Kuboki, Y., Toyama, T., Miyamoto, Y., Kirihara, T., Hayasake, K., Mitao, A., Monna, L., Zhong, H.S., Tamura, Y., Wang, Z.X., Momma, T., Umehara, Y., Yano, M., Sasaki, T., and Minobe, Y. 1994. A 300 kilobase interval genetic map of rice including 883 expressed sequences. Nat. Genet. 8: 365-372.

Lallemand, J., Lem, P., Ghesquiere, M., Charmet, G., and Balfourier, F. 1998. Potentiality of STS for variety distinction in ryegrass. In Report of the 5th Session of theWorking Group on Biochemical and Molecular Techniques and DNA Profiling in Particular, 28-30 September 1998, Beltsville, Md. The International Union for the Protection of New Varieties of Plants (UPOV), Geneva. Rep. No. BMT/S/11.

Lander, E.S., Green, P., Abrahamson, J., Barlow, A., Daly, M.J., Lincoln, S.E., and Newburg, L. 1987. MAPMAKER: an interactive computer package for constructing primary linkage maps of experimental and natural populations. Genomics, 1: 174-181.

Law, C.N., Sutka, J., and Worland, A.J. 1978. A genetic study of day-length response in wheat. Heredity, 41: 185-191.

Maliepaard, C., Jansen, J., and Van Ooijen, J.W. 1994. Linkage analysis in a full-sib family of an outbreeding plant species: overview and consequences for applications. Genet. Res. 70: 237-250.

Marino, C.L., Nelson, J.C., Lu, Y.H., Sorrells, M.E., Leroy, P., Tuleen, N.A., Lopes, C.R., and Hart, G.E. 1996. Molecular genetic maps of the group 6 chromosomes of hexaploid wheat (Triticum aestivum L. em. Thell.). Genome, 39: 359-366.

Masterson, J. 1994. Stomatal size in fossil plants: evidence of polyploidy in majority of angiosperms. Science (Washington, D.C.), 264: 421-424.

Miller, J.C., and Tanksley, S.D. 1990. Effects of different restriction enzymes, probe source and probe length on detecting restriction fragment length polymorphism in tomato. Theor. Appl. Genet. 80: 385-389.

Namuth, D.M., Lapitan, N.L.V., Gill, K.S., and Gill, B.S. 1994. Comparative RFLP mapping of Hordeum vulgare and Triticum tauschii. Theor. Appl. Genet. 89: 865-872.

Nelson, J.C., Van Deynze, A.E., Autrique, E., Sorrells, M.E., Lu, Y.H., Merlino, M., Atkinson, M., and Leroy, P. 1995a. Molecular mapping of wheat. Homoeologous group 2. Genome, 38: 516-524.

Nelson, J.C., Van Deynze, A.E., Autrique, E., Sorrells, M.E., Lu, Y.H., Negre, S., Bernard, M., and Leroy, P. 1995b. Molecular mapping of wheat. Homoeologous group 3. Genome, 38: 525533.

Paterson, A.H., Bowers, J.E., Burow, M.D., Draye, X., Elsik, C.G., Jiang, C.-X., Katsar, C.S., Lan, T.-H., Lin, Y.-R., Reiguang, M., and Wright, R.J. 2000. Comparative genomics of plant chromosomes. Plant Cell, 12: 1523-1539.

Pereira, M.G., Lee, M., Bramel-Cox, P., Woodman, W., Doebley, J., and Whitkus, R. 1994. Construction of an RFLP map in sorghum and comparative mapping in maize. Genome, 37: 236243. 
Ritter, E., Gebhardt, C., and Salamini, F. 1990. Estimation of recombination frequencies and construction of RFLP linkage maps in plants from crosses between heterozygous parents. Genetics, 135: 645-654.

Rognli, O.A., Devos, K.H., Chinoy, C.N., Harcourt, R.L., Atkinson, M.D., and Gale, M.D. 1992. RFLP mapping of rye chromosome $7 \mathrm{R}$ reveals a highly translocated chromosome relative to wheat. Genome, 35: 1026-1031.

Sarma, R.N., Fish, L., Gill, B.S., and Snape, J.W. 2000. Physical characterisation of the homoeologous group 5 chromosomes of wheat in terms of rice linkage blocks, and physical mapping of some important genes. Genome, 43: 191-198.

Sharp, P.J., Kreis, M., Shewry, P.R., and Gale, M.D. 1988. Location of $\beta$-amylase sequences in wheat and its relatives. Theor. Appl. Genet. 75: 286-290.

Shen, L.S., He, P., Xu, Y.B., Tan, Z.B., Lu, C.F., and Zhu, L.H. 1998. Genetic molecular linkage map construction and genome analysis of a rice doubled haploid population. Acta Bot. Sin. 40: 1115-1122.

Shields, R. 1993. Pastoral synteny. Nature (London), 365: 297298.

Soreng, R.J., and Davis, J.I. 1998. Phylogenetics and character evolution in the grass family (Poaceae): simultaneous analysis of morphological and chloroplast DNA restriction site character sets. Bot. Rev. 64: 1-85.

Stam, P., and van Ooijen, J.W. 1995. JOINMAP ${ }^{\mathrm{TM}}$ version 2.0. Software for the calculation of genetic linkage maps. CPRODLO, Wageningen, The Netherlands.
Stebbins, G.L. 1966. Chromosomal variation and evolution: polyploidy and chromosome size and number shed light on evolutionary processes in higher plants. Science (Washington, D.C.), 152: 1463-1469.

Van Deynze, A.E., Dubcovsky, J., Gill, K.S., Nelson, J.C., Sorrells, M.E., Dvořák, J., Gill, B.S., Lagudah, E.S., McCouch, S.R., and Appels, R. 1995a. Molecular genetic maps for group 1 chromosomes of Triticeae species and their relation to chromosomes in rice and oat. Genome, 38: 45-59.

Van Deynze, A.E., Nelson, J.C., O’Donoghue, L.S., Ahn, S., Siripoonwiwat, W., Harrington, S.E., Yglesias, E.S., Braga, D.P., McCouch, S.R., and Sorrells, M.E. 1995b. Comparative mapping in grasses. Oat relationships. Mol. Gen. Genet. 249: 349356.

Van Deynze, A.E., Nelson, J.C., Yglesias, E.S., Harrington, S.E., Braga, D.P., McCouch, S.R., and Sorrells, M.E. 1995c. Comparative mapping in grasses. Wheat relationships. Mol. Gen. Genet. 248: $744-754$.

Van Deynze, A.E., Sorrells, M.E., Park, W.D., Ayres, N.M., Fu, H., Cartinhour, S.W., Paul, E., and McCouch, S.R. 1998. Anchor probes for comparative mapping of grass genera. Theor. Appl. Genet. 97: 356-369.

Wang, Z.Y., and Tanksley, S.D. 1989. Restriction fragment length polymorphism in Oryza sativa L. Genome, 32: 1113-1118.

Zhang, H., Liu, X., Jia, J.Z., Gale, M.D., and Devos, K.M. 1998. Relationships between the chromosomes of Aegilops umbellata and wheat. Theor. Appl. Genet. 96: 69-75. 